\title{
Safety and Diagnostic Accuracy of Dobutamine Stress Echocardiography
}

\author{
Shah RK1* \\ ${ }^{*}$ Department of Cardiology, NAMS, Bir Hospital, Kathmandu, Nepal \\ Corresponding: Dr. Ram Kishor Shah \\ Department of Cardiology National Academy of Medical Sciences, Bir Hospital, P.O.Box. 8011, Kathmandu, Nepal. \\ Email - rkshah40@yahoo.com
}

\begin{abstract}
Exercise and pharmacologic stress echocardiography has been used routinely in clinical practice for the past twenty to thirty years. Dobutamine stress echocardiography (DSE) is well established as a safe, feasible, and accurate modality for detection of myocardial ischemia and prognostication in patients with known or suspected coronary artery disease, particularly when they have limited exercise capacity. Serious side effects during or shortly after DSE are uncommon, with ventricular fibrillation or myocardial infarction occurring in approximately 1 of 2,000 studies. No deaths have been reported. On the basis of a total number of 2,246 patients, reported in 28 studies, the sensitivity, specificity and accuracy of the test for the detection of coronary artery disease (CAD) were $80 \%, 84 \%$ and $81 \%$, respectively. Mean sensitivities for one, two and three-vessel disease were $74 \%, 86 \%$ and $92 \%$, respectively. The sensitivity of detection of disease in the let circumflex coronary artery $(55 \%)$ was lower, both compared with that for left anterior descending (72\%) and right coronary artery disease (76\%). The sensitivity of predicting multivessel disease by multiregional echocardiographic abnormalities varied widely, from $8 \%$ to $71 \%$. In direct comparisons, DSE was superior to exercise electrocardiography and dipyridamole echocardiography and comparable to exercise echocardiography and radionuclide imaging. DSE is useful, feasible and safe exercise independent stress modality for assessing the presence, localization and extent of CAD.
\end{abstract}

Keywords : coronary artery disease; dobutamine stress echocardiography.

\section{INTRODUCTION}

Coronary arteriography is widely accepted as a gold standard for the diagnosis of coronary artery disease (CAD) and the evaluation of the extent and severity of vessel stenoses. Non-invasive diagnostic tests detect the consequences of ischemia: impaired cell membrane function, decreased perfusion and impaired myocardial contractility. Exercise and pharmacologic stress echocardiography have been used routinely in clinical practice for the past twenty to thirty years. 1-3 Over this time, stress echocardiography has become an accepted means of evaluation for perfusion-limiting coronary artery or excluding coronary artery disease in patients with chest pain remains a challenge because this disease is still the leading cause of death in the western world. 4 traditionally, exercise electrocardiography is performed as a first-line nonivasive diagnostic stress test. 5 However, large numbers of patients referred for evaluation of chest pain are unable to perform adequate diagnostic exercise testing. Mainly due to decongitioning or neurologic, respiratory, peripheral vascular or orthopedic limitations. 6 In these patients, Dobutamine stress echocardiography (DSE) represents an alternative, exercise-independent stress modality. Dobutamine stress echocardiography (DSE) is well established as a safe, feasible, and accurate modality for detection of myocardial ischemia and prognostication in patients with known or suspected coronary artery disease, particularly when they have limited exercise capacity. 7-12
Dobutamine: pharmacology and mechanism of action.

Dobutamine is aa synthetic catecholamine with a relatively short plasma half-life of 2 minutes due to rapid metabolization in the liver to inactive metabolites. 13,14 It has a strong beta1receptor and mild alpha1- and beta2-receptor agonist activity. When used at low dose (up to $10 \mathrm{ig} / \mathrm{kg}$ body weight per min), marked inotropic effects (mediated by both alpha1- and beta1- receptor stimulation) are encountered. When used at high dose (20 to $40 \mathrm{ig} / \mathrm{kg}$ per min), heart rate is progressively increased (mediated by beta1-receptor stimulation). Systemic blood pressure increases only minimally due to an combined effect of increase in cardiac output and a decrease in systemic vascular resistance. In patients without a sufficient increase in heart rate, the addition of atropine has been proposed tofurther increase heart rate by its vagolytic effects. 15 As a result of the hemodynamic changes there is an increase in oxygen demand. However, in myocardial regions supplied by a coronary artery with a critical stenosis, the increase in oxygen demand cannot be met by an adequate increase in blood flow. 15 Hence, regional ischemia develops and causes regional wall motion abnormalities that can be detected by two-dimensional echocardiography.17-43

\section{Protocol}

Protocols for DSE vary from institution to institution, particularly with regard to dobutamine dose (range 20 to 40 $\mathrm{ig} / \mathrm{kg}$ per $\mathrm{min}$ ), atropine addition (range 0 to $2 \mathrm{mg}$ ) and stage 
duration (range 2 to $8 \mathrm{~min}$ ), 17-45 Centres that use lower peak doses of dobutamine use longer stage durations and stop betaadrenergic blocking agent treatment more often before the test. The most widely used protocol uses dobutamine up to $40 \mathrm{ig} / \mathrm{kg}$ per min, with the addition of atropine up to $1 \mathrm{mg}$. 15 According to this protocol, a resting electrocardiogram (ECG) and twodimensional echocardiogram are acquired, intravenous access is secured, and dobutamine is then administered intravenously by an infusion pump, starting at 5 or $10 \mathrm{~g} / \mathrm{kg}$ per $\mathrm{min}$ for $3 \mathrm{~min}$, increasing by $10 \mathrm{ig} / \mathrm{kg}$ per min every $3 \mathrm{~min}$ up to a maximum of $40 \mathrm{ig} / \mathrm{kg}$ per min. in patients not achieving $85 \%$ of their predicted maximal heart rate $(220$ beats/min minus age for men, beats/min 200 minus age for women) and without symptoms or signs of myocardial ischemia, atropine is administered on top o fthe maximal dose of dobutamine; starting with $0.25 \mathrm{mg}$ intravenously and repeated up to a maximum of $1.0 \mathrm{mg}$ within $4 \mathrm{~min}$, with continuation of dobutamine infusion. Throughout dobutamine infusion, the ECG (12 leads) is continuously monitored and recorded at 1 minute intervals. Blood pressure is measured and recorded by sphygmanometry or automatic device every $3 \mathrm{~min}$. the echocardiogram is continuously monitored and recorded on video or quad screen during the final minute of each dobutamine (or atropine) stage and recovery.

\section{Reasons for'Termination of the test are:}

1. Severe or extensive new wall motion abnormalities.

2. Horizontal or downsloping ST segment depression $>0.2$ $\mathrm{mV}$ at an interval of $80 \mathrm{~ms}$ after the j point compared with baseline.

3. ST segment elevation $>0.1 \mathrm{mv}$ in patients without a previous myocardial infarction.

4. Severe angina.

5. A symptomatic reduction in systolic blood pressure e 40 $\mathrm{mm} \mathrm{Hg}$ from baseline.

6. Hypertension (blood pressure e 240/120 mm Hg).

\section{Contraindications to DSE include}

1. Critical aortic stenosis

2. Hypertrophic cardiomyopathy

3. Uncontrolled hypertension

4. Uncontrolled atrial fibrillation

5. Known severe ventricular arrhythmias and electrolyte abnormalities (mainly hypokalemiz). 46,47

6. the addition of atropine is contraindicated in patients with narrow-angle glaucoma. Myasthenia gravis, obstructive uropathy or obstructive gastrointestinal disorders.

\section{Echocardiographic interpretation}

The left ventricle is usually divided into the 16 segment model recommended by the American Society of Echocardiography. ${ }^{48}$ Although the quad screen format (with rest, low and high dose and recovery images next to each other in one screen) facilitates wall motion analysis, it is not a prerequisite because videotape analysis seems to be as reliable.

$1=$ normal, characterized by a uniform increase in wall exvursion and thickening

$2=$ hypokinesiaa, denoted by reduced $(<5 \mathrm{~mm})$ inward systolic wall motion

$3=$ akinesia, is marked by an absence of inward motion and

\author{
thickening \\ $4=$ dyskinesia, indicated by systolic thinning and outward \\ systolic wall motion
}

A normal stress echocardiogram is defined by a uniform increase in wall motion and systolic wall thickening, with a reduction in end-systolic cavity area.

A positive test is denoted by development of new wall motion dyssynergy or by worsening of regional dyssynergy in one or more segments.

\section{Other possible dobutamine-induced markers of inchemia}

\section{Abnormal left ventricular diastolic filling}

Changes in diastolic indexes are known to precede systolic changes and therefore may be a more sensitive indicator of myocardial ischemia. 50

\section{Sinus node deceleration.}

Dobutamine stress-induced sinus node deceleration, defined as an initial increase and subsequent decrease in heart rate with progressive dobutamine infusion, occurs more often during dobutamine infusion than during exercise. 51

\section{Mitral regurgitation}

The development of new or worsening mitral regurgitation with stress doses of dobutamine. 24,52

\section{Hypotension}

It may result from

1) An inadequate increase in cardiac output to compensate for an expected decrease in systemic vascular resistance, 53,54

2) A disproportionate decrease in systemic vascular resistance in the presence of a normal increase in cardiac output.

\section{ECG changes}

Whereas ST segment changes are the hallmark of ischemia in exercise tests. They seen to have less value during dobutamine stress. 5

\section{Feasibility and safety}

In $5 \%$ of patients, an inadequate acoustic window precludes the performance of successful DSE. 10\% of tests are non diagnostic (absence of ischemic markers in submaximal tests) 55,56 because of an insufficient hemodynamic response to dobutamine/atropine administration or limiting side effects.

\section{Adverse effects}

Non cardiac side effects (nausea, headache, chills, urgency and anxiety) are usually well tolerated, without the need for test termination.

The most common cardiovascular side effects

1. Angina occurs in $20 \%$ of patients 55,57

2. Dobutamine stress-induced hypotension occurs, depending on its definition, in $5 \%$ to $37 \%$ of patients 54,58-61

3. Arrhythmias are not uncommon 55,57, with frequent premature atrial or ventricular contractions occurring in 
$10 \%$ of patients

4. Supraventricular or ventricular tachycardias each occurring in $4 \%$ of patients.

5. On the basis of combined diagnostic and safety reports on DSE $17-43,55-57$ it can be roughly estimated that ventricular fibrillation or MI occurs in 1 out of 2,000 studies.

6. Atropine intoxication, although generally requiring a dose of atropine of at least $5 \mathrm{mg}$, has been reported in a few patients receiving d" $1 \mathrm{mg}$ of atropine

7. Fatal events were not reported

\section{Intra observer and inter observer agreement.}

Intra observer and inter observer agreement for ischemia within institutes as reported in individual studies $18,19,31,34,36,42$ ranged from $95 \%$ to $98 \%$ and from $92 \%$ to $96 \%$, respectively.

Agreement was clearly higher in patients without CAD or with extensive CAD and was lower in patients with limited echocardiographic image quality.

\section{Diagnostic Accuracy}

\section{Detection of CAD}

As with other testes for detection of $\mathrm{CAD}$, the diagnostic accuracy of DSE is expressed by its sensitivity, specificity and accuracy.

The overall (weighted mean) sensitivity, specificity and accuracy of DSE for a total of 2,246 patients in 28 published studies $17-43$ was $80 \%$ (95\% confidence interval [CI] $78 \%$ to $82 \%$ ), $84 \%$ ( $95 \%$ CI $82 \%$ to $86 \%$ ) and $81 \%$ (95\% CI $79 \%$ to $83 \%)$, respectively. When only the 17 largest series from single centers were included 19-43 (thus avoiding potential double counting of previously included patients from the same center in an earlier report), these respective numbers were, for a total of 1,454 patients, $81 \%$ (95\% CI $79 \%$ to $84 \%$ ), $85 \%$ (95\% CI $82 \%$ to $87 \%$ ) and $82 \%$ (95\% CI $80 \%$ to $85 \%$ ). The normalcy rate was reported to be $92 \% 62$.

One of the most important avoidable factors influencing test sensitivity is the use of beta blockers. These medications lower peak cardiac work load and inotropic response during DSE and thus have the potential to lower the sensitivity of the test, especially when atropine is not added to dobutamine. 63

\section{Detection of disease in individual coronary arteries}

Based on the known anatomic relations between coronary arteries and various myocardial regions, general guidelines have been developed for the assignment of these myocardial regions to specific coronary arteries. It is therefore possible to infer disease of a given coronary artery by noting the location of a wall motion abnormality on echocardiography. The mean reported 24,32,37,42 sensitivities were $72 \%, 55 \%$ and $76 \%$, respectively, and the mean specificities were $88 \%, 93 \%$ and $89 \%$, respectively.

\section{Identification of extensive $\mathrm{CAD}$}

An important goal of noninvasive stress testing is the identification of patients with left main or threevessel CAD.

Patients with multi-vessel disease can be differentiated from patients with single-vessel disease by detection of echocardiographic abnormalities in two or more coronary territories.

Investigators who examined the prediction of multivessel disease by this method 17,19,24,26,29,37 consistently reported a high specificity (range $90 \%$ to $100 \%$ ). However, the sensitivity of DSE for the prediction of multivessel disease varied markedly from $8 \%$ to $71 \%$. Several factors contribute to the underestimation of multivessel disease: inadequate stress protocols, the premature cessatio of stress because of the development of limiting ischemia in one region, imperfect assignment of myocardial regions to coronary arteries, collateral circulations and anatomically significant but functionally non significant lesions. Recent reports have shown that DSE provides other, unique features to identify multivessel disease, by measuring the ischemic threshold and left ventricular volume changes.

Patients with left bundle branch block or left ventricular hypertrophy.

The ability of noninvasive tests to diagnose or localize CAD in patients with left bundle branch block (LBBB) or left ventricular hypertrophy (LVH) has been disappointing.

Exercise-induced changes on the ECG are non diagnostic in the presence of LBBB 64 and lack specificity in the presence of $\mathrm{LVH}$, even in the absence of baseline ECG abnormalities 65

Reports on the use of DSE in patients with LBBB or LVH are scarce. Small studies including patients without a previous MI and LBBB reported a sensitivity of $80 \%$, a specificity of $87 \%$ and an accuracy of $85 \% .65,66$

These small studies require confirmation from larger series to firmly establish the diagnostic value of DSE in patients with LBBB or LVH.

Comparison with other stress modalities in patients able to exercise adequately

\section{Exercise electrocardiography}

Pooled data from eight studies 20,24,31,34-37,41 directly comparing DSE and exercise electrocardiography in the same 560 patients show that the sensitivity $(76 \%$ vs. $63 \%, \mathrm{p}<0.0001)$, specificity ( $88 \%$ vs. $64 \%, \mathrm{p}<0.0001)$ and accuracy $(79 \%$ vs. $63 \%, \mathrm{p}<0.0001)$ of DSE was clearly superior. However, since most studies did not specify how many patients were able to exercise adequately, were using digoxin or had abnormal rest ECG result, these results do not indicate that the routine exercise test should be replaced by DSE.

\section{Exercise echocardiography}

Pooled data from four studies 3436,41 directly comparing DSE and exercise echocardiography in the same 334 patients show that the sensitivity ( $75 \%$ vs. $85 \%, \mathrm{p}<0.01)$ and accuracy $(79 \%$ vs. $86 \%, p<0.05)$ of exercise echocardiography were significantly higher. It should be emphasized that these differences were caused by one particular study in which DSE showed low accuracy. 35 In that study a large number of DSE tests were sub-maximal because a modest decline in systolic blood pressure was used as a, not uncommon, end point, and a substantial number of the study patients were using betablockers while atropine was not added to dobutamine.

Comparison with other stress modalities in patients unable to exercise adequately

Dipyridamole echocardiography

In patients unable to perform adequate exercise, 
echocardiographic imaging can also be perfomed with dipyridamole as a pharmacologic stressor. 16 In normal arteries dipyridamole, an indirect coronary vasodilator, causes a threeto fivefold increase in both subendocardial and subepicardial coronary flow. 67 However in stenosed arteries this augmentation is limited (depending on stenosis severity),creating flow heterogeneity. Echocardiographically detected functional evidence os ischemia is not caused by marked changes in blood pressure or heat rate (which change only minimally to moderately) but by coronary steal, either "vertical" (subepicardium from subendocardium)68 or "horizontal" (nonstenotic from stenotic vessel territory) 69 pooled data from six studies $21,25,31,38,39,41$ directly comparing DSE and dipyridamole echocardiography showed that DSE is more sensitive for the detection of CAD ( $73 \%$ vs. $65 \%, \mathrm{p}<0.05)$, mainly because of a higher sensitivity in patients with single-vessel disease. The specificity ( $82 \%$ vs. $89 \%$ ) and accuracy ( $76 \%$ vs. $72 \%$ ) of the respective tests were not significantly different. Recent reports 43,70 have suggested that the addition of atropine to dipyridamole increase the sensitivity of the dipyridamole test for the detection of CAD to a level comparable with dobutamine-atropine stress echocardiography. 71

\section{Radionuclide imaging}

During dobutamine stress, coronary blood flow to the vascular bed of a normal artery increases dramatically, whereas perfusion through a stenosed artery may change minimally.

On the basis of this induction in regional flow heterogeneity, the dobutamine stress test can also be performed in conjunction with radionuclide perfusion imaging.

In four studies 72-75 comparing DSE with dobutamine technetium-99mm (Tc-99m) imaging in 318 patients, sensitivity was $76 \%$ versus $81 \%$, specificity $85 \%$ versus $71 \%$ (p $<0.01$ ) and accuracy $80 \%$ versus $78 \%$

The finding that DSE is more specific but may be less sensitive (especially in patients with single-vessel disease) is in line with the "ischemic cascade" theory 86 , which states that perfusion abnormalities due to limited coronary flow reserve precede echocardiographic and ECG changes.

DSE and radionuclide perfusion imaging seem to have comparable diagnostic accuracy, and the choice of one test over the other can be based on patient characteristics and the competence of the laboratory performing the test 10 .

\section{Patients after MI}

The major goals of DSE in patients with a previous MI are to assess infarct-ralated coronary artery patency and to identify patients with multivessel CAD.

Smart et al. 77 reported in a large series of patients, with use of the "biphasic" response, a sensitivity of $82 \%$, a specificity of $80 \%$ and a diagnostic accuracy of $82 \%$ for the detection of infarct-related coronary artery stenosis.

The presence of multivessel CAD in patients with a previous MI should ideally be based on an ischemic response in two coronary vascular territories. However, an approach in which remote ischemia (ischemia detected outside the infarct-related coronary artery territory) is considered diagnostic for multivessel CAD also seems valid because in most of these patients the infarct-related coronary artery is also significantly narrowed.

\section{Future Developments}

At present, the major limitations of DSE are endocardial border definition and subjective interpretation of stress- induced wall motion abnormalities. Enhancement of border definition (and thus interpretation) in currently under investigation with gray-scale B-mode color encoding, 78 intravenous contrast agents, 79 tissue Doppler interrogation, 80 tissue characterization techniques and backscatter analysis. 61 Eventually, the result of these investigations should lead to improved automatic border detection and objective (computerized), realistic criteria for wall motion abnormalities diagnostic of CAD. 82,83

\section{CONCLUSION}

DSE is a feasible, safe and useful exercise-independent stress modality for assessing the presence, localization and extent of CAD. The diagnostic accuracy of DSE seems at least comparable to other, competitive noninvasive stress modalities used in patients with limited exercise capacity. New technical developments are expected to further increase its strengths and should make the interpretation of stress echocardiograms more uniform and less subjective.

\section{REFRENCES}

1. Sawada SG, Judson WE, Ryan T. Armstrong WF. Feigenbaum H. Upright bicycle exercise echocardiography after coronary artery bypass grafting. Am j Cardiol, 1989; 64: 1123-1129.

2. Bolte HD. Pharmacologic testing of heart function. Internist, 1977; 18: 571-578.

3. Borow Km, Green LH, Grossman W, Braunwald E. Left ventricular end-systolic stress-shortening and stresslength relations in human. Normal values and sensitivity to inotropic state. Am J Cardiol, 1982; 50: 1301-1308.

4. Morbidity from Coronary Heart Disease in the United States: National Heart, Lung, and Blood Institute Data Fact Sheet. Bethesda (MD): $\{1\}$ National Heart, Lung, and Blood Institute, 1990.

5. Chaitman BR. The changing role of the exercise electrocardiogram as a diagnostic and prognostic test for chronic ischemic heart disease. J Am Coll Cardiol 1986;8:1195-210.

6. Marwick T. Current status of non-invasive techniques for the diagnosis of myocardial ischemia. Acta Clin Belg 19992;47:1-5.

7. Kamaran M, Teague SM, Finkelhor RS et al. prognostic value of doubtmine stress echocardiography in patients referred because of suspected coronary artery desease. AM J Cardiol, 1995; 76: 887-891.

8. Poldermans D, Fioretti PM, Boersma E et al. Longterm prognostic value of dobutamine - atropinestress echocardiography in 1737 patients with known or suspected coronary artery disease: a single-center experience. Circulation, 1999; 99: 757-762.

9. Steinberg EH, Madmon L, Patel CP et al. Long-term prognostic signficance of dobutamine echocardiography in patients with suspected coronary artery disease: results of a 5-year follow-up study j Am Coll Cardiol, 1997; 29: 969-973.

10. Quantitative detection of myocardial ischaemia by stress echocardiography; a comparison with SPECT. Gudmundesson P, Shahgaidi K, Winter R, Dencker M, Kitlinski M, Thorsson O, Willenheimer RB, Ljunggren L. Cardiovasc Ultrasound. 2009 Jun 18;7:28.

11. the value of contrast dobutamine stress echocardiography on detecting coronary artery disease in overweight and 
obsess patients, Hu SJ, Liu SX Katus HA, Luedde M, Can J Cardiol, 2007 Sep; 23(11);88-9

12. Myocardial viability assessed by dobutamine stress echocardiography predicts reduced mortality early after acute myocardial infarction; determining the risk of events after myocardial infarction (DREAM) study. Swinburn JM, Senior R. Heart, 2006 Jan;92(1) 44-8 Epub 2005 Apr 14.

13. Ruffolo RR. The pharmacology of dobutamine. Am J MEd 1987;294:244-8.

14. Meyer SL, CUrry GC, Donesey MS, Twieg DB, Parkey RW, Willerson JT. Influence of dobutamine on hemodynamics and coronary blood flow in patients with and without coronary artery disease. Am J Cardiol 1976;38: 103-8.

15. McNeill Aj, Fioretti PM, EI-Said EM, Salustri A, Forster T, Roelandt JRTC. Enhanced sensitivity for detection of coronary artery disease by addition of atropine to dobutamine stress echocardiography. Am J Cardiol 1992;70:41-6.

16. Fung AY, Gallagher KP, Buda AJ. The physiologic basis of dobutamine as compared with dipyridamole stress interventions in the assessment of critical coronary stenosis. Circulation 1987;76:943-54.

17. Sawada SG, Segar DS, Ryan T, et al. Echocardiographic detection of coronary artery disease during dobutamine infusion. Circulation 1991;83: 1605-14.

18. Previtali M, Lanzatini L, Ferrario M, Tortorici M, Mussini A, Montemartini C, Dobutamine versus dipyridamole in coronary artery disease. Circulation 1991 Suppl III:III-27-31.

19. Cohen Jl, Greene TO, OTtenweller J, Binenbaum SZ, Wilchfort SD, Kim CS Dobutamine digital echocardiography for detecting coronary artery disease. Am J Caridol 1991;67:1311-8.

20. Salustri A, Fioretti PM, Pozzoli MMA, McNeill AJ, Roelandt JRTC. Dobutamine stress echocardiography: its role in the diagnosis of coronary artery disease. Eur Heart J 1992;13:70-7.

21. Martin TW, Seawoth JF, Johns JP, Pupa LE, Condos WR. Comparison of adenosine, dipyridamole, and dobutamine in stress echocardiography. Ann intern Med 1992;116:190-6.

22. Segar DS, Brown SE, Sawada SG, Ryan T, Feigenbaum H. Dobutamine stress echocardiography: correlation with coronary lesion severity as determined by quantitative angiography. J Am Coll Cardiol 1992;19:1197-202.

23. Marcovitz PA, Armstrong WF. Accuracy of dobutamine stress echocardiography in detecting coronary artery disease. Am J Cardiol 1992;69:1269-73.

24. Mazeika PK, Nadazdin A, Oakley CM. dobytamine stress echocardiography for detection and assessment of coronary artery disease. J Am Coll Cardiol 1992;19:120311.

25. Salustri A, Fioretti PM, McNeill AJ, Pozzoli MMA, RoelandtJRTC.Pharmacological stress echocardiography in the diagnosis of coronary artery disease and myocardial ischemia: a comparison between dobutamine and dipyridamole. Eur Heart J 1992;13:1356-62.

26. Marwick T, Willemart B, D'Hondt Am, et al. Selection of the optimal nonexercise stress for the evaluation of ischemic regional myocardial dysfunction and malperfusion: comparison of dobutamine and adenosine using echocardiography and $99 \mathrm{~m}$ Tc-MIBI single photon emission computed tomography. Circulation 1993;87:345-54.

27. Gu"nalp B, Dokumaci B, Uyan C, et al. Value of dobutamine technetium- $99 \mathrm{~m}$ setamibi SPECT and echocardiography in the detection of coronary artery disease compared with coronary angiography. J Nucl Med 1993;34:889-94.

28. Forster T, McNeill Aj, Salustri A, et al. Simulataneous dobutamine stress echocardiography and $99 \mathrm{~m}$-technetium isonitrile single-photon emission computed tomography in patients with suspected coronary artery disease. J Am Coll Cardiol 1993;21:1591-67.

29. Marwick t, D'Hondt AM, Baudhuin T, et al. Optimal use of dobutamine stress for the detection and evaluation of coronary artery disease: combination with echocardiography or scintigraphy, or both? J Am Coll Cardiol 1993;22:159-67.

30. Hoffmann $R$, Lethen $H$, Kleinhans $E$, Weiss $M$, Flachskampf FA, Hanrath P. Comparative evaluation of bicycle electrocardiogram for identification of coronary artery disease. Am J Cardiol 1993;72:555-9.

31. Previtali M, Lanzarini L, Fetiveau R, et al. Comparison of dobutamine stress echocardiography, dipyridamole stress echocardiography and exercise stress testing for diagnosis of coronary artery disease. Am J Cardiol 1993;72:865-70.

32. Takeuchi $M$, Arki $M$, nakashima $Y$, Kuroiwa A. comparison of dobutamine stress echocardiography and stress thallium-201 single-photon emission computed tomography for detecting coronary artery disease. J Am Soc Echocardiogr 1993;6:593-803.

33. Cohen JL, Ottenweller JE, George Ak Duvvuri S. Comparison of dobutamine and exercise echocardiography for detecting coronary artery disease. Am J Cardiol 1993;14:799-803.

34. Cohen JL, Ottteweller JE, George Ak, Duvvuri S. comparison of dobytamine and exercise echocardiography for detecting coronary artery disease. Am J Cardiol 1993;72:1226-31.

35. Marwick TH, D'Hondt AM, Mairesse GH, et al. Comparative ability of dobutamine and exercise stress in inducing myocardial ischemia in active patients. Br Heart J 1994;72:31-8.

36. Beleslin BD, Ostojic M, Stepanovic J, et al. Stress echocardiography in the dtection of myocardial ischemia: head-to-head comparison of exercise, dobutamine, and dipyridamole tests. Circulation 1994;90:1168-76.

37. Senior R, Sridhara BS, Anagnostou E, Handler C, Raftery EB, Lahiri A Synergistic value of simultaneous stress dobutamine sestamibi singlephoton- emission computerized tomography and echocardiography in the detection of coronary artery disease. Am Heart J 1994;128:713-8.

38. Sochowski RA, Yvorchuk KJ, Yang YY, Rattes MF, Chan KL. Dobut- 604 GELEIJNSE ET AL. JACC Vol. 30 No. 3 DOBUTAMINE STRESS ECHOCARDIOGRAPHY September 1997;595-606 amine and dipyridamole stress echocardiography in patients with a low incidence of severe coronary artery disease. J Am Soc Echocardiogr 1995;8:482-7.

39. Ostojic M, Picano E, Beleslin B, et al. D i p y r i d a m o l e - d o b u t a m i n e echocardiography: a novel test for the detection of milder forms of coronary artery desease. J Am Coll Cardiol 1994:23:1115-22.

40. Daoud EG, Pitt A, Armstrong WF. Electrocardiographic 
response during dobutamine stress echocardiography. Am Heart J 1995;129:672-7.

41. Dagianti A, Penco M, Agati L, et al. Stress echocardiography: comparison of exercise, dipyridamole and dobutamine in detecting and predicting the extent of coronary artery disease. J Am Coll Cardiol 1995;26:1825.

42. Ho FM, Huang PJ, Liau CS, et al. Dobutamine stress echocardiography compared with dipyridamole thllium-201 single-photon emission computed tomography in detecting coronary artery disease. Eur Heart J 1995;16:570-5.

43. Pingitore A, Picano E, Quarta Colosso M, et al. The atropine factor in pharmacologic stress echocardiography. J Am Coll Cardiol 1996;27:1164-70.

44. Pellikka PA, Roger VL, Oh JK, Miller FA, Seward JB, Tajik J. Stress echocardiography part II. Dobutamine stress echocardiography; techniques, implementation, clinical applications, and correlations. Mayo Clin Proc 1995;70:16-27.

45. Safety and cardiac chronotropic responsiveness to the early injection of atropine during dobutamine stress echocardiography in the elderly, Tsutsui JM, Larjo FC, Femades DR, Kowatsch 1, Sbano JC, Franchini Ramires JA, Mathias W Jr. Heart, 2005 Dec;9(12): 1563-7, Epub 2005 Mar 29.

46. Williams ME, Gervino EV, Rosa RM, et al. Carecholamine modulation of rapid potassium shifts during exercise. $\mathrm{N}$ Engl J Med 1985;312:823-7.

47. Coma-Canella I. Changes in plasma potassium during the dobutamine stress test. Int J Cardiol 1991;33L55-60.

48. American Society of Echocardiography Commitee on Standards (Subcommittee on Quantitation) of TwoDimensional Echocardiograms). Recommendations of quantification of the left ventricle by two-dimensional echocardiography. J Am Soc Echocardiogr 1989;16:14204.

49. Castini D, Gentile F, Ornaghi $M$, et al. Dobutamineechocardiography: usefullness of digital image processing Eur Heart J 1995;16:1420-4.

50. Labovitz AJ, Lewen MK, Kern M, Vandormael M, Deligonal U, Kennedly HL. Evaluation of left ventricular systolic and diastolic dysfunction during transient myocardial ischemia produced by angioplasty. J Am Coll Cardiol 1987;10:784-55.

51. Hopfenspirger MR, Miller TD, Christian TF, Gibbons RJ. Sinus node deceleration during dobutamine perfusion scintigraphy as a marker of inferior ischemia. Am J Cardiol 1994;74:817-9.

52. Dobutamine stress echocardiography unmasks acute woresening of mitral regurgitation with latent left ventricular outflow tract obstruction behind diastolic heart failure in hypertensive heart disease. Fujino M, Kanzaki H, Tanaka J, Ohara T, Kim J, Hashimura K, Nakatani S, Ikeda Y, Ueda-Ishibashi H, Kitakaze M, Intern Med. 2009, 48 (2) : 95-9 Epub 2009 Jan 15.

53. Tanomoto M, Pai RG, Jintapakorn W. Normal changes in left ventricular filling and hemodynamics during dobutamine stress echocardiography. J Am Soc Echocardogr 1995;8:488-93.

54. Tanimoto M, Pai RG, Jintapakorn W, Shah PM. Mechanism of hypotension during dobutamine stress echocardiography in patients with coronary artery disease. Am J Cardiol 1995;76:26-30.
55. Poldermans D, Fioretti PM, Boersma E, et al. Safety of dobutamineatropine stress echocardiography in patients with suspected or proven coronary artery disease: experience in 650 consecutive examinations. Am J Cardiol 1994;344:1190-2.

56. Picano E, Mathias W Jr, Pingitore R, Bigi R, Previtali M. Safety and tolerability of dobutamine-atropine stress echocardiography: a prospective, multicentre study. Lancet 1994;344:1190-2.

57. Mertes H, Sawada SG, Ryan T, et al. Symptoms, adverse effects, and complications associated with dobutamine stress echocardiography: experience in 1118 patients. Circulation 1993;88:15-9.

58. Heinle SK, Tice FD, Kisslo J. Hypotension during stress echocardiography: is it related to dynamic intraventricular obstruction? Am Heart J 1995;130:3147.

59. Marcovitz PA, Bach DS, Mathias W, Shayana V,Armstrong WF, Paradoxic hypotension during dobutamine stress echocardiography: clinical and diagnostic implications. J Am Coll Cardiol 19993;21:1080-6.

60. Lieberman EB, Heinle SK, Wildermann N, Waugh $\mathrm{Ra}$, Kisslo JA, Bashore TM, Does hypotension during dobutamine stress echocardiography correlate with anatomic or functional cardiac impairment? Am Heart J 1995; 129:1121-6.

61. Geleijnse ML, Elhendy A, Van Domburg RT, et al. Prognostic significance of systolic blood pressure changes during dobutamine-atropine stress technetium-99m sestamini perfusion scintigraphy in patients with chest pain and known or suspected coronary artery disease. Am J Cardiol 1997;79: 1031-5.

62. Bach DS, Hepner A, Marcovita PA, Armstrong WF, Dobutamine stress echocardiography: prevalence of a nonischemic response in a low-risk population. Am Heart J 1993;125:1257-61.

63. Fioretti PM, Poldermans D, Salustri A, et al. Atropine increases the accuracy of dobutamine stress echocardiography in patients taking betablockers. Eur Heart J 1994;15:355-60.

64. Orzan F, Garcia E, Mathur VS, Hall RJ. Is the treadmill exercise test useful for evaluating coronary artery disease in patients with complete left bundle branch block? Am J Cardiol 1978;42:36-40.

65. Senior R, Basu S, Handler C, Raferty EB, Lahiri A, Diagnostic accuracy of dobutamine stress echocardiography for detection of coronary heart disease in hypertensive patients. Eur Heart J 1996;17:289-95.

66. Mairesse GH, marwick TH, Arnese M, et al. Improved identification of coronary artery disease in patients with left bundle branch block by use of dobutamine stress echocardiography and comparison with myocardial perfusion tomography. Am J Cardiol 1995:76:321-5.

67. Wilson RF, Wyche K, Christensen BV Zimmer S, Laxson DD. Effect of adenosine on huma coronary arterial circulation. Circulation 1990;82: 1595-606.

68. Flameng $W$, Wunsten B, Schaper $W$. On the distribution of myocardial blood flow: II. Effects of arterial stenosis and vasodilation. Basis Res Cardiol 1974;69:435-46.

69. Demer L, Gould KL, Kirkeeide R. Assessing stenosis severity: coronary flow reserve, collateral function, quantitative coronary arteriography, positron imaging, and digital subtraction angiography: a review and analysis. Prog Cardiovasc Dis 1988;30:307-22.

70. picano E, Pingitore A, Conti U, et al. Enhanced sensitivity 
for detection of coronary artery disease by addition of atropine to dipridamole echocardiography. Eur heart J 1993;14:1216-22.

71. Quantitative myocardial contrast echocardiography during pharmacological stress for diagnosis of coronary artery disease: a systematic review and meta-analysis of diagnostic accuracy studies. Abdelmoneim SS, Dhoble A, Bernier M, Erwin PJ, Korosoglou G, Senior R, Moir S, Kowatsch I, Xian-Hong S, Muro T, Dawson D, Vogel R, Wei K, west CP, Montori VM, Pellikka PA, Abdel-Kader SS, Mulvagh SL, Eur J Echocardiogr. 2009 Jun 23. (\{Epub ahed of print

72. Takeuchi M, Araki M, Nakashima Y, Kuroiwa . The detection of residual ischemia and stenosis in patients with acute myocardial infarction with dobutamine stress echocardiography. J Am Soc Echocardiogr 1994;7:24252.

73. Bigi R, Occhi G, Fiorentini C, et al. Dobutamine stress echocardiography for the identification of multivessel coronary artery disease after uncomplicated myocardial infarction: the importance of test end-point. Int J cardiology 1995;50:51-60.

74. Elhendy A, Van Domburg RT, Roelandt JRTC, et al. Accuracy of dobutamine stress ecgocardiography for the diagnosis of coronary artery stenosis in patients with myocardial infarction: the impact of extent and severity of left ventricular dysfunction. Heart 1996;76:123-8.

75. Elhendy A, Geleijnse ML, Roelandt JRTC et al. Comparison of dobutamine stress echocardiography and 99m-technetium sestamini SPECT myocardial perfusion scintigraphy for predicting extent of coronary artery disease in patients with healed myocardial infarction. Am J Cardiol 1997;79:7-12.

76. nesto RW, Kowalchuck GJ. The ischemic cascade: temporal sequence of hemodynamic, electrocardiographic and symptomatic expressions of ischemia. Am J Cardiol 1987;57:23C-7C.

77. Smart SC, Knickelbine T, Stoiber TR, Carlos M, Wynsen JC, Sagar KB. Safety and accuracy of dobutamineatropine stress echocardiography for the detection of residual stenosis of the infarct-related artery and multivessel disease during the first week after acute myocardial infarction. Circulation 1997;95:1394-401.

78. Marcovitz PA, back DS, Bach DS, Segar DS, Armstrong $W$. Impact of B-mode color encoding on rapid detection of ultrasound targets: an in vitro study. J Am Soc Echocardiogr 1993;6:382-6.

79. Crouse LJ, Cheirif J, Hanly DE, et al. Opacification and border delineation improvement in patients with suboptimal endocardial border definition in routine echocardiography: results of the phase III Albunex multicenter trail. J Am Coll Cardiol 1993;22:1494-500.

80. Palka P, Lange A, Fleming AD, Sutherland GR, Fenn LN, McDicken NW. Doppler tissue imaging: myocardial wall motion velocities in normal subjects. J Am Soc Echocardiogr 1995;8:659-68.

81. milunski MR, Mohr GA, Perez JE, et al. Ultrasonic tissue characterization with intergrated backscatter: acute myocardial ischemia, reprefusion, and stunned myocardium in patients. Circulation 1989;80:491-503.

82. CCarstensen S Ali SM, Stensgaard-Hansen FV et al. Dobutamine-atropine stress echocardiography in asymptomatic healthy individuals: the relativity of stress induced hyperkinesias. Circulation 1995;923453-63.

83. Real-time three-dimensional myocardial contrast echocardiography : is it clinically feasible? Bhan A Kapetanaki S, Rana BS, Ho E, Wilson K, Person P, Mushemi s, Deguzman J, Reiken J, Harden MD, Walker N, Rafter PG, Monaghan MJ, Ecur J Echocardiogr. 2008 Nov;9(6) -5, Epub 2008 May 1. 